Tumour angiogenesis is a crucial factor associated with tumour growth, progression, and metastasis. The whole process is the result of an interaction between a wide range of different molecules, influencing each other. Herein we summarize novel discoveries related to the less known angiogenic molecules such as galectins, pentraxin-3, Ral-interacting protein of $76 \mathrm{kDa}$ (RLIP76), long non-coding RNAs (IncRNAs), B7-H3, and delta-like ligand-4 (DLL-4) and their role in the process of tumour angiogenesis. These molecules influence the most important molecular pathways involved in the formation of blood vessels in cancer, including the vascular endothelial growth factor (VEGF)-vascular endothelial growth factor receptor interaction (VEGFR), HIF1- $\alpha$ activation, or PI3K/Akt/ mTOR and JAK-STAT signalling pathways. Increased expression of galectins, RLIP76, and B7H3 has been proven in several malignancies. Pentraxin-3, which appears to inhibit tumour angiogenesis, shows reduced expression in tumour tissues. Anti-angiogenic treatment based mainly on VEGF inhibition has proved to be of limited effectiveness, leading to the development of drug resistance. The newly discovered molecules are of great interest as a potential source of new anti-cancer therapies. Their role as targets for new drugs and as prognostic markers in neoplasms is discussed in this review.

Key words: angiogenesis, carcinogenesis, galectins.

Contemp Oncol (Pozn) 2021; 25 (1): 33-44 DOI:https://doi.org/10.5114/wo.2021.105075

\section{The complexity of tumour angiogenesis based on recently described molecules}

\author{
Weronika Wiśniewska ${ }^{1}$, Michał Kopka $^{1}$, Karolina Siemiątkowska ${ }^{1}$, \\ Marta Magdalena Fudalej ${ }^{2,3}$, Aleksandra Sobiborowicz ${ }^{1}$, \\ Anna Maria Badowska-Kozakiewicz ${ }^{2}$
}

'Students' Scientific Organization of Cancer Cell Biology, Department of Cancer Prevention, Medical University of Warsaw, Warsaw, Poland

${ }^{2}$ Department of Cancer Prevention, Medical University of Warsaw, Warsaw, Poland ${ }^{3}$ Doctoral School, Medical University of Warsaw, Warsaw, Poland

\section{Introduction}

Angiogenesis is recognized to play a crucial role in tumour growth, progression, and metastasis [1]. It is widely described that tumours cannot grow beyond $2 \mathrm{~mm}^{3}$ without an adequate supply of nutrients and oxygen via a proper vascular system [2]. Many molecular pathways are directly related to angiogenesis, but only some of them have been extensively studied and described so far [3]. The main role in this process is attributed to angiogenic molecules such as vascular endothelial growth factor (VEGF), fibroblast growth factor-2 (FGF-2), or the platelet-derived growth factor family, but also phenomena such as hypoxia, immune cell activity, or changes in the tumour microenvironment [3]. Progressive knowledge about the extensive role of angiogenesis in cancer has inspired scientists to seek therapies based on inhibiting the growth of the new vessels [4]. However, therapies based mainly on the inhibition of key molecules such as VEGF have proven to be of limited effectiveness, leading to the development of drug resistance [5-7]. This emphasizes the need for further research, to improve anti-angiogenic therapies in the future. Recently, many new molecules that influence the formation of new vessels have been discovered, proving the complexity of this process. In this review, we summarize the latest reports about less known molecules involved in angiogenesis.

\section{Galectins}

Galectins, a family of lectins that bind -galactosides, are generally wellknown due to their role in cell-to-extracellular matrix interactions [8]. They contain one or more evolutionarily conserved carbohydrate-recognition domains (CRDs) - sequences that are responsible for binding to carbohydrates [9]. Recently, a lot of attention has been paid to galectins due to their freshly described multidirectional activity in facilitating the development of malignant tumours [10]. Extracellularly localized galectins interact with the cell-surface and extracellular matrix, while these localized intracellularly influence cytoplasmic and nuclear signalling pathways [8]. Moreover, some of them - such as galectin-3 - are present both at the cell surface and inside the cytoplasm, and may be secreted into biological fluids like serum and urine [11]. The galectin-glycan interaction plays an important role in physiological and pathological processes including angiogenesis, regulation of immune response, metastasis, and apoptosis [12-15]. Many of the functions related to angiogenesis such as endothelial cells (EC) activation, proliferation, adhesion, migration, tube formation, and sprouting may be assigned to galectins highly expressed in endothelial cells, such as galectin $-1,-3,-8$, and -9 [16]. 
Galectin-1 (gal-1) is the first described human galectin, and one of the best-studied members of this family. Among many other functions, gal-1 plays a key role in stimulating tumour angiogenesis by inducing endothelial cell proliferation and migration, mirroring the effects of VEGF [17]. Gal-1 has the ability to bind N-glycans complex on vascular endothelial growth factor receptor 2 (VEGFR2), which results in increased phosphorylation and activation of kinases Akt and Erk1/2, mimicking the phosphorylation pattern following VEGF-VEGFR interaction [17]. Moreover, gal-1 can act as an independent pro-angiogenic growth factor, indirectly inducing pro-angiogenic signalling by stimulating VEGFR2 clustering or increasing receptor membrane retention. In addition, in murine models, Gal-1 was found to be increasingly secreted by tumours resistant to anti-VEGF agents $[16,17]$. A study by van Beijnum et al. [18] revealed that inhibition of gal-1 by specific antibodies inhibits sprouting angiogenesis both in vitro and in vivo.

In tumour vessels, Gal-1 expression was found to be increased in comparison to vessels in healthy tissue. Elevated gal-1 expression has been described in neoplastic cells of lung [19], prostate [20], oral cancer [21], and gliomas [22]. Recently, it was also described to be overexpressed in the tumour tissue of renal cell carcinoma [23]. High expression of gal-1 is associated with poor overall survival (OS) in hepatocellular carcinoma (HCC), colorectal, gastric, and pancreatic cancer. In these malignancies, gal-1 is up-regulated in both tumour-associated stromal cells and epithelial cells [24]. Moreover, gal-1 overexpression is associated with resistance to sorafenib (a tyrosine kinase inhibitor of, among others, VEGFR-2 and VEGFR-3), poor tumour control, and low response rate in HCC [25]. In gastric cancer, gal-1 is highly expressed by cancer-associated fibroblasts (CAFs), and it was shown to facilitate the interaction between CAFs and human umbilical vein endothelial cells, stimulating their proliferation, migration, and tube formation in vitro [26]. Similarly, in human multiple myeloma, gal-1 expression was shown to be regulated by hypoxia-inducible factor $1 \alpha$ (HIF-1 $\alpha$ ), and its suppression resulted in reduced angiogenesis and bone lesion formations in vivo in 2 different murine models [27]. Gal-1 secreted by human omental microvascular endothelial cells (HOMECS) in metastasized high-grade serous carcinoma (HGSC) of the ovary was proven to increase the number of microvessels in omental metastases, potentially via the MEK/ERK1/2 signalling pathway [28]. Moreover, in pancreatic ductal adenocarcinoma (PDA), gal-1 mediates the action of human pancreatic stellate cells (HPSCS), which encompass the stimulation of cancer proliferation, migration, and invasion. In PDA murine models, gal-1 knock-out diminished metastasis rates and prolonged survival [29].

These discoveries prompted research assessing the potential use of gal-1 inhibitors, targeting gal-1 contribution to angiogenesis, as a possible anti-cancer treatment option. One of the gal-1 inhibitors is an artificial, non-specific peptide, Anginex, which, among other properties, binds to gal-1, inhibits its function, and stops gal-1 uptake by EC [30]. Many clinical studies revealed the synergistic effect of Anginex treatment in combination with radiotherapy [31, 32] or chemotherapy [33]. Koonce et al. [34] used a non-peptidic galectin-1 inhibitor OTX008 in human head and neck squamous cell carcinoma (HNSCC) models, and its administration resulted in tumour vessel normalization and tumour reoxygenation, which may improve HNSCC susceptibility to radio- and chemotherapy. Another molecule that is promising for designing specific galectin antagonists is lactulose. Its derivatives showed the ability to bind galectin-1 and galectin-3 carbohydrate recognition domains [35]. Gal-1 can also be a target for specific, designed antibodies, used as therapeutic and diagnostic agents [18]. Finally, as was mentioned in the case of sorafenib resistance in HCC, gal-1 may be responsible for limited benefits of anti-VEGF treatment, and therefore, targeting gal-1 may improve the effectiveness of anti-VEGF therapies [17].

Galectin-3 (gal-3) is a unique member of the family of galectins. Structurally, gal-3 contains a proline- and glycine-rich N-terminal domain, enabling it to form oligomers. In addition, gal-3 may be localized in the cytoplasm, on the cell surface, or as a free form in biological fluids like serum [36]. Galectin-3 was also identified as a receptor for advanced glycosylation end products (AGE). However, gal-3 plays a receptor role not independently but rather in association with other AGE receptors [37]. Moreover, in the tumour microenvironment, it takes part in neo-vascularization by several molecular mechanisms, which include VEGFR2 retention and activation, integrin $\alpha V \beta 3$ activation and promotion of angiogenesis by the basic fibroblast growth factor (bFGF), VEGF, and neuron-glial antigen 2 (NG2) signalling pathways [38, 39]. In addition, under hypoxic conditions, gal-3 is released by neoplastic cells and increasingly binds to ECs, which activates the JAG1/Notch signalling pathway and triggers angiogenic sprouting [39]. The biological function of Gal-3 is highly dependent on its ability to multimerize and to bind to many glycoproteins. Gal-3 is involved in the process of formation of signalling platforms on the cellular membrane, that contain receptors of other molecules, including those that induce angiogenesis [40]. In this sense, Gal-3 is responsible for the amplification of the signal and acts as an important cofactor [41]. Gal-3 can promote vessel formation not only by direct interaction with EC but also indirectly, by stimulating macrophages and platelets to release VEGF [41].

The increased endothelial gal-3 expression has been reported in hepatic, pancreatic, oral, thyroid, bladder, and gastric carcinoma [42]. Recently, it was also found to be upregulated in clear cell, chromophobe, and papillary renal cell carcinomas [43]. However, increased expression of gal-3 is not universally observed in malignancies, as other studies described down-regulation of gal-3 in the tumour tissue of the breast, prostate, cervical, and endometrial carcinoma [42, 44]. Serum levels of gal-3 from patients with lung, thyroid, hepatocellular, prostate, bladder, breast, renal, gastrointestinal, and head and neck carcinomas were significantly elevated when compared to those in healthy individuals [11, 42]. Circulating galectin-3 plays an important role in metastasis and angiogenesis by mediating cancer cell-endothelial adhesion via interacting with mucins: MUC1 and MUC4. Gal-3 inhibitors were shown to 
inhibit the development of lung metastases of melanoma and colon cancer in murine models [45].

Gal-3 is a putative therapeutic target for anti-cancer therapies; thus, many molecules were synthesized to bind to gal-3 and inhibit its pleiotropic actions. Because of the fact that galectins have a high affinity for carbohydrates [8], inhibitors, based on carbohydrate scaffolds, such as galactose, lactose, or talose [46], and gal-3-binding neo-glycoproteins [47] were designed. Polysaccharides such as modified citrus pectin (MCP) [48], corn pectic polysaccharide (COPP) [49], arabinogalactan HH1-1 derived from safflower [50] and RN1, purified from the flower of Panax [51], generate high affinity to gal-3 and demonstrate promising results as anti-cancer agents. In a study by Nangia-Makker et al. [52], MCP inhibited capillary tube formation in vitro and tumour growth, angiogenesis, and spontaneous metastasis in vivo in mice. MCP activity was also evaluated in patients with various solid tumours, showing a positive impact on some of them [53]. COPP in the study conducted by Jayaram et al. [49] decreased the level of VEGF, matrix metallopeptidase 2 (MMP-2), and matrix metallopeptidase 9 (MMP-9) in the tumour tissue and inhibited metastasis in vivo. $\mathrm{HH} 1-1$ presented anti-cancer activity in PDA in vitro and in vivo, as it binds to gal-3, impairs the interaction between gal-3 and epidermal growth factor receptor (EGFR), and inhibits the galectin-3/EGFR/AKT/FOXO3 signalling pathway [50]. RN-1 activity, similarly to $\mathrm{HH} 1-1$, was also evaluated in PDA, showing inhibition of tumour cells growth both in vitro and in vivo, affecting multiple gal-3-associated signalling pathways [51]. Heparin derivates also pose as promising gal-3 binding agents - chemically modified heparin molecule does not show anticoagulant activity, but it destabilizes the structure of galectin-3 and, as a result, stops tumour progression in vitro and reduces metastasis in a murine model $[45,54]$. Another molecule, galectin-3C, a truncated, dominant-negative form of galectin-3, is a competitive inhibitor of endogenous gal-3, which was shown to decrease endothelial cells tubule formation in vitro [55], and to be a putative treatment option for multiple myeloma and ovarian cancer $[56,57]$. Finally, bergenin, a substance isolated from plants used in South Asian traditional medicine, was computationally proven to have an affinity for gal-3, and it could potentially be used to develop new anti-cancer therapies in the future [58].

Galectin-8 (gal-8), as a result of alternative splicing, occurs in 7 isoforms [59] and is expressed in several human carcinomas, including ovarian [60], prostate [61], and breast cancer [62]. It was found to induce angiogenesis, at least partially, via cross-linking of activated leukocyte cell adhesion molecule (ALCAM, CD166) [57, 59, 63]. The serum level of gal-8 is higher in patients with colorectal and breast cancer, especially with metastatic disease, when compared to healthy individuals [59]. In contrast to gal-1, galectin-8 expression was not reported to be up-regulated in tumour EC in response to anti-VEGF therapy [59]. Circulating gal-8 was reported to be responsible for increased secretion of other pro-angiogenic factors such as granulocyte colony-stimulating factor (G-CSF), interleukin 6 (IL-6), and monocyte chemoattractant protein-1 (MCP-1) [64]. Moreover, gal-8 has recently been proven to induce epithe- lial-mesenchymal transition by activating the FAK/EGFR/ proteasome pathway in Madin-Darby canine kidney cells [65]. Gal-8 can also increase endothelial hyperpermeability through the destabilization of adherens junctions via S-nitrosylation mediated by nitric oxide synthase (eNOS), which was confirmed both in vitro and in vivo [66].

Galectin-9 up-regulation, and therefore increased expression, was described in kidney, lung, and liver tumour vessels [16]. Gal-9 may be expressed by EC in 5 different splice variants [16]. The effects of gal-9 actions depend on the different variables including splice variant, concentration, environment, and cellular context [67]. The best described, dominant form is galectin-9 95 , and it can either promote or suppress angiogenesis, depending on the circumstances $[67,68]$. In the study conducted by Aanhane et al. [69], all gal-9 isoforms inhibited angiogenesis in vivo in contrast to the previously described galectins. However, Enninga et al. [70] showed that gal-9 binds to CD206 on M2 macrophages, and they suggested that this interaction may increase the secretion of pro-angiogenic factors and chemokines from myeloid cells. This divergent information underlines the necessity of further investigation to assess the effect of galectin-9 on both angiogenesis and carcinogenesis.

\section{Pentraxin-3}

Pentraxin-3 (PTX3/TSG14) is a member of the family of pentraxins, which is divided into short and long pentraxins [71]. The short pentraxin subfamily includes proteins such as C-reactive protein (CRP) and serum amyloid $P$ component (SAP), well known for their important role in innate immunity [71]. PTX3, which belongs to the long pentraxin subfamily, is produced by innate immunity cells in response to inflammatory signals and acts as a multifunctional soluble pattern recognition receptor [72]. Its essential role in immunity, pathogen recognition, complement activation, and inflammation is well established [73, 74], but recent studies have revealed that it may also play an important inhibitory role in angiogenesis [75].

PTX3 binds with high affinity to FGF-2, one of the most important angiogenic factors [76], sequestering it and preventing it from activating its receptors on endothelial cells [77]. This interaction results in the inhibition of FGF2-dependent proliferation of endothelial cells in vitro and in vivo [76]. PTX3 activity was assessed in prostate cancer, highly dependent on FGF2 stimulation, revealing PTX3 anti-angiogenic and anti-neoplastic activity in vitro and in vivo [78]. Moreover, PTX3 expression was proven to be present in cells in healthy prostate but completely absent in high-grade prostate cancer, suggesting that the loss of its function may play an important role in tumour progression [78]. PTX-3 was found to inhibit the growth of fibrosarcoma in vitro and in vivo, by decreasing cell proliferation and tumour vascularization [79]. Its overexpression causes significant changes in the tumour microenvironment, reducing inflammatory infiltrate and vascular density in a murine model of fibrosarcoma [80]. In 2015, Ronca et al. found that overexpression of PTX3 inhibits angiogenesis, metastasis, and tumour growth in a transgenic 
mouse model, and identified NSC12 - a small PTX3 derivative that acts as an FGF2 trap, that performs similar activity [81]. NSC12 was proven to be a promising therapeutic molecule because it inhibited cell proliferation and reduced fibroblast growth factor receptor 1 (FGFR1) and fibroblast growth factor receptor 3 (FGFR3) activation in fibrosarcoma models in vitro and in vivo [79]. It also impaired tumour growth and vascularization in a murine model of prostate cancer [82] and tumour growth of murine and human lung cancer cells in vitro and in vivo [83]. FGF trapping by PTX3 and NSC12 was also evaluated as a therapeutic strategy in murine melanoma model and human uveal melanoma cell lines, revealing inhibition of proliferation, survival, and migration of melanoma cells [84]. PTX3 may also bind to fibroblast growth factor-8b (FGF8b) and inhibit the activation of its receptor. Consequently, PTX3 inhibits the FGF8b-induced neovascularization and growth of hormonal tumours [85].

Even though most studies suggest an anti-angiogenic role of PTX3 in cancer, in 2016, Hida et al. [86] found that PTX3 is overexpressed in mouse and human tumour endothelial cells (TECS) in comparison to normal endothelial cells. Moreover, in the same study, knockdown of PTX3 inhibited TECs proliferation. PTX3 was also proven to have some pro-tumour effects in multiple tumours [75]. PTX3 promotes tumour cell migration in the pancreatic carcinoma cell lines, and its elevated level correlates with advanced clinical stage and poor prognosis in pancreatic carcinoma [87]. In cervical cancer, high expression of PTX3 is positively correlated with higher tumour grade and cell proliferation, invasion, and migration in human cervical HeLa cells [88]. Moreover, PTX3 knockdown inhibited tumour growth in vitro and tumourigenesis and metastasis in vivo [88]. PTX3 is expressed by tumour cells in glioma, and its level corresponds with the high-grade and severity of the tumour $[89,90]$. Elevated levels of PTX3 were found in the serum of patients with prostate cancer [91] and lung carcinoma [92] and in tumour tissue of human soft tissue liposarcoma [93]. EGF-induced PTX3 promotes metastasis in HNSCC by regulating the expression of fibronectin, E-cadherin, and MMP-9 [94]. In gastric cancer [95] and breast cancer [96] PTX3 contributes to osteolysis and bone metastasis. That is why it remains unclear whether PTX3 plays a negative or positive role in the development of the tumour. These findings suggest that its action might depend on the tumour type and microenvironment [75].

\section{RLIP76}

The ral-interacting protein of $76 \mathrm{kDa}$ (RLIP76), known also as Ral-binding protein 1 (RalBP1), occurs in different compartments of the cell, including the cell membrane, intracellular fluid, and the nucleus [97, 98]. The primary structure of RLIP76 might be divided into four main regions: the N-terminal region, the Rho-Gap region, the Ral binding region, and the C-terminal region [97]. Originally, RLIP76 was identified as a Ral GTPase effector protein, which links Ral to the Rho pathways [99]. Expression of RLIP76 was reported in a variety of human tissues, e.g. liver, heart, lung, kidney, ovary, and muscles [97, 99]. RLIP76 is a stress-responsive multifunctional protein, involved in processes such as apoptosis, cell proliferation, differentiation, migration, and metabolite transport [97, 98, 100]. It consists of 2 ATP binding sites (in the N-terminal region and C-terminal regions) and is able to catalyse the transport and conjugation of glutathione and xenobiotics across the biological membranes, contributing to anti-apoptosis and multidrug resistance mechanisms in cancer cells [97-99]. RLIP76 overexpression was observed in numerous malignancies such as non-small cell lung carcinoma, colon carcinoma, prostate cancer, melanomas, gliomas, meningiomas, breast cancer, and pancreatic cancer [97-99, 101-103].

RLIP76 is an essential mediator of angiogenesis and tumour growth associated with another basic angiogenesis mediator - VEGF. In the study by Wang et al. RLIP76 suppression in an unexplored mechanism decreased the VEGF secretion and VEGF-induced tube formation in vitro [100]. The angiogenic roles of RLIP76 are presumed to involve a combination of effects on VEGF expression through HIF-1 activation, and on VEGF secretion, possibly through regulation of phosphoinositide 3-kinase (PI3K) [99]. In neoplastic cells, VEGF transcription is induced by HIF-1 [104]. RLIP76 stimulates PI3 kinase - the element of the PI3K/Akt/mTOR signalling pathway that promotes the activation of HIF-1. In the nucleus, HIF-1 binds its cofactor and then the whole complex stimulates the expression of target genes, including VEGF $[97,99]$.

Moreover, RLIP76 was found to regulate the angiogenic response of epithelial cells. Studies implemented on RLIP76 knock-out mice, based on a 3D reconstruction of tumour vasculature, determined that in RLIP76-knockout mice the central tumour vessels and their branches were shorter and narrower compared to wild type mice [98]. In the implanted tumours in RLIP76-knockout mice, angiogenesis was inhibited. The potential mechanism was associated with the role of RLIP76 in efficient migration, proliferation, and cord formation of endothelial cells. Defects in endothelial cell function, due to the absence of RLIP76, lead to ineffective angiogenesis [98, 99].

Cell migration and spreading are necessary during angiogenesis. RLIP76 participates in these processes by regulating the Ras-related $\mathrm{C} 3$ botulinum toxin substrate 1 (Rac1) and ADP ribosylation factor 6 (Arf6) signalling pathways. On the molecular level, after pro-angiogenic stimulation, RLIP76 binds R-Ras in a GTP-dependent manner. This leads to the formation of R-Ras-dependent trisphosphate (PIP3), which contributes to the recruitment of a guanine nucleotide exchange factor for Arf6 (ARNO). The interaction between RLIP76 and ARNO enhances the activation of Arf6. Consequently, the activated Arf6 GTPase leads to the promotion of Rac1 GTPase activation. Given all the connections, RLIP76 plays a crucial role as a link in a small GTPase downstream effect in Rac1 and Arf6 pathway, being essential for tumour angiogenesis [98, 105, 106].

RLIP76 overexpression was indicated in samples derived from patients suffering from breast cancer and was positively correlated with the malignant status of these patients and associated with poor prognosis. Therefore, 
some studies indicate that RLIP76 overexpression should be considered as a biomarker of poor prognosis in breast cancer [107]. The newest studies concerning breast cancer indicate a promising role of 2'-hydroxyflavanone (2HF), associated with RLIP76, in oncological therapies. Flavonoids are compounds ubiquitously present in many foods and beverages of plant origin. $2 \mathrm{HF}$ is a novel natural small phytochemical with no declared toxicity towards normal tissues $[102,108]$. Administration of $2 \mathrm{HF}$ was shown to inhibit the development of triple-negative breast tumours in the mice xenograft model, which was correlated, among other effects, with RLIP76 suppression [102]. In the study by Singhal et al., it was confirmed that $2 \mathrm{HF}$ may suppress breast cancer by targeting RLIP76 both in vivo and in vitro. Because 2HF decreases RLIP76 and VEGF expression and regulates critical proliferative and differentiation proteins, $2 \mathrm{HF}$ may be proposed as an improvement of breast cancer treatment schemes $[109,110]$.

The expression of RLIP76 is positively correlated with the pathological stages of meningiomas - the highest level was observed in anaplastic meningiomas classified as grade III according to the WHO [103]. Moreover, some studies suggest that discussed overexpression might lead to a highly proliferating phenotype due to its significant correlation with the proliferation marker Ki-67. Given all the information, patients suffering from meningiomas with high expression of RLIP76 are in the group of shorter recurrence-free survival (RFS), which was confirmed in the study by Fan et al. [103]. Apart from the angiogenic role of RLIP76, the possible mechanism associating RLIP76 with poor prognosis relates to apoptosis inhibition through interactions with a spectrum of functionally distinct proteins, encompassing Caspase 3 and $\mathrm{Bcl}-2[103,111]$.

\section{LnCRNA}

Long non-coding RNAs (LncRNAs) are a group of ribonucleic acids consisting of more than 200 base pairs, which might be transcribed by RNA polymerase II and then undergo co-transcriptional modifications (i.e. polyadenylation or pre-RNA splicing), but they mostly cannot be translated into proteins [112-114]. They might possess their promoters and be localized between protein-coding genes (intergenic) [112]. It has been discovered that IncRNAs are involved in various conditions, e.g. hypoxia and hyperglycaemia [112]. LncRNA presents 3 main mechanisms of action.

1. LncRNA may fold into a tertiary structure and supply a scaffold for the formation of a quaternary structure for proteins and regulatory RNA [112]. LncRNAs can serve as adaptors to bring 2 or more proteins into discrete complexes. The primary example of scaffolds is HOX transcript antisense intergenic RNA (HOTAIR) simultaneously binding both polycomb repressive complex 2 (PRC2) and a complex of lysine-specific demethylase 1 (LSD1) and corepressor protein - COREST. Consequently, this combination ensures gene silencing through histone $\mathrm{H} 3$ lysine 27 (H3K27) methylation and histone H3 lysine 4 (H3K4) demethylation [115]

2. LncRNA regulates the gene expression at the posttranscriptional level [112]. LncRNAs control processes such as RNA maturation and transport or protein synthesis. They affect the stability of mRNAs and might compete for miRNA-mediated inhibitor or function as a miRNA precursor. These attributes of IncRNAs lead to increased mRNA expression [116].

3. LncRNA may directly bind DNA sequences and form RNA-DNA triplex complex [112]. Forming these complexes may represent a type of epigenetic regulation in which IncRNA serves as a molecular guide, described as "decoys" $[115,116]$.

Nevertheless, it must be underlined that there are probably many other mechanisms of IncRNA action to be discovered. In most tissues, the expression level of IncRNA is lower than that of mRNA [112], apart from the brain, in which the expression level of IncRNA is higher than that of mRNA [112]. LncRNAs may be located in the nucleus (IncRNA Heih, Hotair, 18 Malat1, 19 Evf-2,20 Lethe21, and Xist22), in the cytoplasm (IncRNA Ptenp1 Ror, HULC, lincMD1, 1/2-sbs RNAs, and Gadd, LncRNA Tincr), or in both the nucleus and the cytoplasm [112, 114]. It is suspected that the specific function of IncRNAs is related to their subcellular localization [117].

LncRNA can promote and inhibit angiogenesis, drug resistance, and proliferation. Importantly, their role in drug resistance affects the main treatment strategies in oncology: chemotherapy, hormone therapy, targeted therapy, and immunotherapy [118]. Moreover, IncRNAs and miRNAs (e.g. miR-345-5p) participate in epithelial-mesenchymal transition (EMT), cell growth, and angiogenesis in multiple cancers: gastric, thyroid, breast, bladder, and non-small cell lung cancer [119]. LncRNAs also regulate synapse formation, reprogramming of human-induced pluripotent stem cells, nuclear organization, nuclear-cytoplasmic trafficking, and promote pluripotency and neuronal differentiation [112, 117]. LncRNAs such as HOTAIR, Tie-1AS, and IncRNA, associated with microvascular invasion in HCC (IncRNA MVIH), metastasis-associated lung adenocarcinoma transcript 1 (MALAT1), F630028010Rik (F63), highly up-regulated in liver cancer (HULC), and maternally expressed gene 3 (MEG3), play an important role in angiogenesis [112, 117, 120, 121].

In the studies conducted both in vivo and in vitro on nasopharyngeal carcinoma cells, the HOTAIR directly activates the transcription of VEGF-A and indirectly through immunoglobulin protein (BiP) mediates up-regulation of VEGF-A and angiopoietin-2 (Ang2) expression, which leads to the promotion of angiogenesis [121]. Furthermore, HOTAIR can promote cancer progression through negative regulation of chromosomal transcription or recombination of the chromatin [117]. Significant overexpression of HOTAIR in HCC tissues is correlated with the poor prognosis of the patients, and it predicts tumour recurrence. In HCC cell lines, HOTAIR can downregulate RNA binding motif protein-38 and promote cell invasion and migration. Moreover, it is suggested that HOTAIR ucRNA takes part in an intercellular signalling mediator of growth because its presence was observed in extracellular vesicles released from HCC cells [113].

In endothelial cells, hyperglycaemia and hypoxia increase the level of MALAT1. It was reported that the genetic deletion of the MALAT1 gene leads to reduced retinal 
vascular growth and endothelial growth in experiments in vivo $[122,123]$. Moreover, during pharmacological inhibition of MALAT1, blood-flow recovery and capillary density after hind-limb ischaemia are reduced due to impaired expression of cell cycle regulators [124]. MALAT1, through interacting with miR20416, modulates proliferation, migration, and invasion of cholangiocarcinoma cells [119].

The tie-1AS causes specific defects in endothelial cell contact junctions and tube formations through selective binding to tie-1 mRNA and regulation of its transcription [125]. MVIH inhibits the secretion of phosphoglycerate kinase 1 (PKG1). It is correlated with reduced serum PKG1 levels and leads to increased microvessel density in HCC patients and promotes angiogenesis [126]. HULC knockdown suppresses angiogenesis via the PI3K/Akt/mTOR/ ESM-1 signaling pathway [127].

Differentiation Antagonizing Non-Protein Coding RNA (DANCR) participates in cell progression in various cancers, and thus DANCR is predicted as an emerging therapeutic target in human malignancies [119, 128, 129]. In the study by Zhu et al. [119], it was proven that inhibition of the mentioned IncRNA could inhibit cholangiocarcinoma cell proliferation, migration, and invasion and induce apoptosis. Angiogenesis was inhibited after the silencing of DANCR in the studied samples. The possible mechanism of this phenomenon was related to the association between DANCR and the expression of VEGF-A. The crucial role of VEGF-A during DANCR inhibition of the tumour angiogenesis was also proven in studies conducted on ovarian cancer cells [130].

Plasmacytoma variant translocation 1 (PVT1), a IncRNA encoded by the human PVT1 gene, is in the well-known cancer-connected region. The role of PVT1 as a cancer biomarker is gradually becoming established [131]. The upreg- ulation of PVT1 has been confirmed in studies conducted on tissues derived from patients suffering from gastric cancer [132]. In the study by Zhao et al. [120] it was proven that PVT1 can promote angiogenesis in gastric cancer, for the first time. The results of the mentioned research indicated that PVT1 activates the STAT3 signalling pathway, and consequently elevates the expression of VEGF-A. The mechanism of action of PVT1 is quite complex. PVT1 can directly bind activated p-STAT3 protein and enhance its stability by disrupting its poly-ubiquitination and sequential proteasomal proteolysis. Nuclear p-STAT binds with the VEGF-A promoter and leads to the expression of VEGF-A protein, inducing angiogenesis [120].

The existence of IncRNA inhibiting angiogenesis was proved in the latest studies. Qin et al. [117] discovered a new IncRNA called F630028010Rik (abbreviated as F63), which inhibits VEGF-A secretion, endothelial cell clone formation, migration, invasion, and tube formation.

LncRNAs take part not only in cancer angiogenesis but also in the other aspects of vascularization, encompassing heart development, which was shown in various studies [133-135].

LncRNA might also interact with microRNA (miRNA). It was established that IncRNA may serve as an endogenous sponge to regulate the function and expression of miRNA. On the other hand, miRNA binds to IncRNA, regulating their stability. LncRNA might also compete with other RNA transcripts for the same miRNA and, as a result, perform the function of a competing endogenous RNA (ceRNA), which leads to interactions and subsequent regulation. Furthermore, the existence of many IncRNA/miRNA pathways, playing an important role in angiogenesis (e.g. SNHG1/miR199a, SNHG12/miR-199a), has been discovered recently

\section{Table 1. Functions of IncRNAs}

\begin{tabular}{|c|c|}
\hline LncRNA & Function \\
\hline HOTAIR & $\begin{array}{l}\text { Binds simultaneously with PRC2, LSD1, and CoREST and ensures gene silencing through H3K27 methylation and H3K4 } \\
\text { demethylation [115] } \\
\text { Promotes angiogenesis via direct and indirect up-regulation of VEGF-A expression and indirect up-regulation of Ang2 } \\
\text { expression [121] } \\
\text { Promotes cancer progression through negative regulation of chromosomal transcription or recombination of the } \\
\text { chromatin [117] } \\
\text { Significant overexpression of HOTAIR in HCC tissues correlates with poor prognosis and predicts tumour recurrence [113] }\end{array}$ \\
\hline Tie-1AS & $\begin{array}{l}\text { Plays an important role in angiogenesis via causing a specific defect in endothelial cell contact junctions and tube } \\
\text { formations through selective binding to the tie-1 mRNA and regulation of its translation [125] }\end{array}$ \\
\hline MVIH & Increases microvessel density in HCC patients and promotes angiogenesis via inhibition of the secretion of PKG1 [126] \\
\hline MALAT1 & $\begin{array}{l}\text { Plays an important role in angiogenesis [112] } \\
\text { Through interaction with miR20416 modulates proliferation, migration, and invasion of cholangiocarcinoma cells [119] }\end{array}$ \\
\hline F63 & $\begin{array}{l}\text { Inhibits angiogenesis via supressing VEGF-A secretion and endothelial cells clone formation, migration, invasion, and } \\
\text { tube formation [117] }\end{array}$ \\
\hline MEG3 & Plays an important role in angiogenesis [112] \\
\hline HULC & Its knockdown suppresses angiogenesis via the PI3K/Akt/mTOR/ESM-1 signalling pathway [127] \\
\hline DANCR & $\begin{array}{l}\text { Its inhibition supresses proliferation, migration, and invasion of cholangiocarcinoma cell and induces apoptosis [119] } \\
\text { Its silencing inhibits angiogenesis (an important role may be played here by the association between DANCR and } \\
\text { expression of VEGF-A) }[119,130]\end{array}$ \\
\hline PVT1 & $\begin{array}{l}\text { Promotes angiogenesis in gastric cancer via activation of the STAT3 signalling pathway and consequently elevates the } \\
\text { VEGF-A expression [120] }\end{array}$ \\
\hline
\end{tabular}


[136]. The aforementioned functions of IncRNAs are summarized in Table 1.

\section{B7-H3}

B7-H3, also known as CD276, belongs to the B7-CD28 immune checkpoint family, well-known examples of which include programmed death-ligand 1, CD80, and CD86 [137]. It was first described in 2001 by Chapoval et al. [138]. This transmembrane glycoprotein is mainly expressed by lymphocytes and activated dendritic cells; however, its role in modulating immune response remains unclear because different studies have shown both its inhibitory and co-stimulatory effects on lymphocytes [138]. $\mathrm{B} 7-\mathrm{H} 3$ in humans has 2 isoforms: $2 \operatorname{lgB} 7-\mathrm{H} 3$ and $4 \operatorname{lgB} 7-\mathrm{H} 3$, which is preferentially expressed on immunocytes [139]. It consists of an exon duplication of the extracellular lgVIgC domain, a transmembrane domain, and a short cytoplasmic carboxyl tail without a distinctive signalling motif [140]. High levels of B7-H3 mRNA were found in a wide range of human tissues, while $\mathrm{B} 7-\mathrm{H} 3$ protein is expressed at low levels. It suggests tight post-transcriptional regulation [141], including methylation of B7-H3 promoter and interference with the miRNA-29 family [142]. Expression of $\mathrm{B} 7-\mathrm{H} 3$ was also reported in neoplasms such as lung, prostate, breast, or colorectal cancer [137].

As well as its immunomodulating effects, B7-H3 was recently found to play an important role in angiogenesis, with many potential mechanisms for its involvement described $[143,144]$. High levels of B7-H3 mRNA were observed in late epithelial progenitor cells (LEPCS), a subpopulation of circulating endothelial progenitor cells involved in new vessel formation [143], Son et al. found that B7-H3 facilitates LEPC proliferation and migration in vitro, however, is associated with a decreased rate of angiogenesis and endothelial cell differentiation [143]. Wang et al. showed a correlation of B7-H3 expression and angiogenesis based on analyses of the Chinese Glioma Genome Atlas and the Cancer Genome Atlas datasets [142]. This correlation was further confirmed by in vitro research. In the colorectal cancer model, Wang et al. showed that B7-H3-associated angiogenesis is promoted through NF-kB pathway activation, causing induction of VEGF-A expression [144]. In the cancer angiogenesis context, the NF-kB pathway is known for its role in inflammatory regulation by activation of lymphocytes and macrophages, cell proliferation, and differentiation. A wide range of factors play important roles in signal transduction, especially cytokines - TNF $\alpha$, IL-1, IL-2 [145]. In light of those, the role of NF-kB in cancer development is very complex [146]. Han et al. found that higher expression of $\mathrm{B} 7-\mathrm{H} 3$ was correlated with an increase of transforming growth factor $\beta$ (TGF- $\beta$ ) and interleukin 10 (IL-10) levels in the studied group of mice injected with cervical cancer cells [147]. This may lead to activation of the JAK-STAT pathway and induce the expression of VEGF and promote angiogenesis [148]. Moreover, B7-H3 was shown to directly activate the JAK2/ STAT3 pathway, followed by activation of MMP-9 and Slug transcription factor $[149,150]$. Furthermore, other metastasis-promoting agents such as tissue inhibitors of metalloproteinases 1 and 2 (TIMP1 and TIMP2) and MMP-2 were found to be connected to B7-H3 expression [151]. Lim et al. [152] showed that B7-H3 can inhibit the transcription factor nuclear factor erythroid 2-like 2 (NRF2) [145]. NRF2 is a transcriptional master regulator element that recognizes cellular oxidative stress. Down-regulation of this factor leads to increased reactive oxygen species generation, HIF1- $\alpha$ activation, and VEGF up-regulation $[152,153]$.

B7-H3 expression in tumour tissue was described in different neoplasms, i.e. renal [154], bladder [155], pancreatic [156], cervical [147], and breast cancers [157], sarcomas [158], and gliomas [142]. Higher expression of B7-H3 relates to larger tumour size, infiltrative growth pattern, and poor differentiation of neoplastic cells. In pancreatic cancer, Inamura et al. showed that B7-H3 positive patients had significantly shorter 2- and 5-year-survival: $57 \%$ and $23 \%$ for $\mathrm{B} 7-\mathrm{H} 3(-)$ patients vs. $34 \%$ and $12 \%$ for $\mathrm{B} 7-\mathrm{H} 3(+)$ cases, respectively [156]. In invasive bladder cancer, the presence of $\mathrm{B} 7-\mathrm{H} 3$ expression was associated with even more striking differences in long-term survival - the 5-year-survival rate was $58.1 \%$ for $\mathrm{B} 7-\mathrm{H} 3$-negative patients, while in the B7-H3-positive group it was only $4.5 \%$ [155]. Inamura et al. found that worse prognosis of renal cell carcinoma patients relates to both $\mathrm{B} 7-\mathrm{H} 3$ level and FOXP3+ regulatory $T$ cell density [154].

A novel therapeutic approach using anti-B7-H3 agents was proposed by Bao et al., who showed that combined treatment of murine breast cancer models with anti-PD-1/ PD-L1 agent and photodynamic therapy targeting B7-H3 resulted in suppression of tumour growth, and prevented lung metastasis and recruitment of CD8(+) T cells in tumour mass in comparison with single anti-PD-1/PD-L1 treatment [159]. Based on the results of pre-clinical studies, several phase I clinical trials involving anti-B7-H3

Table 2. The most recent clinical trials involving anti-B7-H3 agents (data from ClinicalTrials.gov)

\begin{tabular}{|c|c|c|c|}
\hline Identifier & Agent/Drug & Description & Status \\
\hline NCT02982941 & Enoblituzumab & Children with $\mathrm{B} 7-\mathrm{H} 3$-expressing solid tumours & Completed \\
\hline NCT04185038 & $\begin{array}{l}\text { B7-H3-Specific } \\
\text { chimeric antigen receptor } \\
\text { T Cell (CAR-T) }\end{array}$ & $\begin{array}{l}\text { Phase } 1 \text { study of B7-H3-specific CAR T cell locoregional immunotherapy } \\
\text { for diffuse intrinsic pontine glioma/diffuse midline glioma and } \\
\text { recurrent or refractory paediatric central nervous system tumours }\end{array}$ & Recruiting \\
\hline NCT04432649 & $\begin{array}{l}\text { CAR-T Cell with 4th } \\
\text { generation B7-H3-specific } \\
\text { chimeric antigen receptor } \\
\text { (4SCAR-276) }\end{array}$ & $\begin{array}{l}\text { T cells genetically modified with a 4th-generation lentiviral chimeric } \\
\text { antigen receptor (4SCAR fused with an inducible apoptotic caspase } \\
9 \text { domain) targeting CD276 (B7-H3). This study will evaluate the side } \\
\text { effects and effective doses of } 4 \text { SCAR-276 in treating refractory and/or } \\
\text { recurrent tumours }\end{array}$ & Recruiting \\
\hline
\end{tabular}


Table 3. Recent anti-DLL-4 agents

\begin{tabular}{|c|c|c|c|c|}
\hline Author & Year & Agent & Study type & Effectiveness \\
\hline $\begin{array}{l}\text { Zhou et al. } \\
\text { [179] }\end{array}$ & 2019 & $\begin{array}{l}\text { HB-32 bispecific } \\
\text { antibody against VEGF } \\
\text { and Dll-4 }\end{array}$ & $\begin{array}{l}\text { Preclinical study, xenograft } \\
\text { breast cancer model }\end{array}$ & $\begin{array}{c}\text { Inhibits HUVEC migration and proliferation. } \\
\text { More effective on cancer cells than } \\
\text { monospecific tested antibodies }\end{array}$ \\
\hline Xu et al. [180] & 2016 & $\begin{array}{l}\text { MMGZ01 anti-Dll-4 } \\
\text { antibody } \\
\text { murine }\end{array}$ & $\begin{array}{l}\text { Preclinical study, xenograft } \\
\text { breast cancer model }\end{array}$ & $\begin{array}{c}\text { Inhibits HUVEC migration and proliferation. } \\
\text { Inhibits angiogenesis and promotes tumour } \\
\text { cell death }\end{array}$ \\
\hline Jia et al. [181] & 2016 & $\begin{array}{l}\text { MMGZ01 anti-Dll-4 } \\
\text { antibody } \\
\text { humanized }\end{array}$ & $\begin{array}{l}\text { Preclinical study, xenograft } \\
\text { breast cancer model }\end{array}$ & $\begin{array}{c}\text { Inhibits HUVEC migration and proliferation. } \\
\text { Inhibits angiogenesis and promotes tumour } \\
\text { cell death }\end{array}$ \\
\hline NCT03292783 & 2017 & $\begin{array}{l}\text { NOV1501(ABLO01) } \\
\text { VEGF/DLL4 targeting } \\
\text { bispecific antibody }\end{array}$ & $\begin{array}{l}\text { Phase I clinical trial; patients } \\
\text { with advanced solid tumours } \\
\text { after failure of standard of care }\end{array}$ & Status: ongoing, unknown \\
\hline $\begin{array}{l}\text { Chiorean } \\
\text { et al. [182] }\end{array}$ & 2015 & $\begin{array}{l}\text { Enoticumab (REGN421) } \\
\text { fully human DIl-4 } \\
\text { antibody }\end{array}$ & $\begin{array}{l}\text { Phase I clinical trial; patients } \\
\text { with ovarian, colon, breast, and } \\
\text { thyroid cancer and sarcomas }\end{array}$ & $\begin{array}{l}36 \% \text { of patients had stable disease as best } \\
\text { response }\end{array}$ \\
\hline
\end{tabular}

agents were carried out or are currently recruiting, as summarized in Table 2.

\section{DLL4-NOTCH}

The Notch family is a group of transmembrane receptors with 4 different members: Notch 1 to 4 , and 5 complementary ligands known in mammals -3 delta-like ligands (DLL 1, 3, 4) and 2 Jagged [160]. Their interactions take part in highly conservative signalling pathways responsible for a wide range of growth and differentiation processes, including angiogenesis $[161,162]$. In this paragraph, we focus on the role of DLL4, because of its recently described potential in cancer therapy.

DLL4 is an endothelial-specific Notch ligand with expression restricted to small arteries and capillaries [162-164]. DLL4 is mainly expressed in arterial endothelial cells, where it is involved in growth, sprouting, and artery specification [165-167]. Muller et al. showed that the presence of DLL4 in tumour tissues has a positive correlation with microvessel density [168]. Interestingly, in a different study, inhibition of the DLL4 pathway was shown to cause an increase of tumour vascular density, but at the same time, newly formed vessels were generally poorly perfused, leading to hypoxia in tumour tissue [169-171].

Complex system of connections between DLL4 and signalling pathways related to angiogenesis include the following: VEGF-A/VEGFR2 [165], Angiopoietin-1 [172], hypoxia-inducible factor $2 \alpha$ (HIF-2 $\alpha$ ) [173], Wnt/ $\beta$-catenin [174], and DLL4 itself [165]. Expression of DLL-4 can mediate the up-regulation of VEGFR1 and down-regulation of VEGFR-2, which causes the 'stalk' phenotype of endothelial cells [175]. Moreover, in a study conducted by Mendoça et al., impairment of DLL4 signalling inhibited EMT by the decrease in Snail, Twist, and TGF- $\beta$ expression [176]. DLL4 may be a potential factor linking hypoxia with EMT, because DLL4 loss-of-function tumour cells did not undergo EMT in a hypoxemic environment [176]. In line with the aforementioned studies, Wang et al. showed that the nonsmall cell lung cancer patients with expression of DLL4 had impaired OS when compared to DLL4-negative patients: $29.4 \pm 16.4$ months and $55.4 \pm 16.1$, respectively [177].
In the last few years, several agents against DLL4 were designed. The short characteristic of preclinical and clinical research assessing their utility is presented in Table 3. Surprisingly, Iwamoto et al. showed that the effectiveness of agents impairing the Notch/DIl4 pathway is dependent on placental growth factor (PIGF) [178].

\section{Conclusions}

The angiogenic factors described in this review have a broad influence on angiogenesis and overall tumour progression. The increased expression of galectins has been reported in several malignancies, and their interaction with VEGFR plays a key role in the formation of new vessels. Recognition of FGF-2 by pentraxin-3 inhibits angiogenesis, but the role of this molecule remains unclear, as some studies suggest its tumour-promoting effects. RLIP76 regulates VEGF expression and secretion in tumour cells through HIF-1 activation. The existence of many IncRNAs playing an important role in angiogenesis (HOTAIR, Tie-1AS, MALAT1, DANCR, PVT1) has been discovered recently. LncRNA both promotes and inhibits angiogenesis, drug resistance, and proliferation. B7$\mathrm{H} 3$ promotes angiogenesis by activating the NF-kB pathway to induce VEGFA expression. DLL4 interacts with important pro-angiogenic molecules such as VEGF-A/VEGFR2, angiopoietin-1, HIF-2 $\alpha$, and Wnt/ $\beta$-catenin. High cancer mortality is driving scientists to seek new treatments, and molecules related to angiogenesis have become promising material for the development of new - and improvement of existing - anti-angiogenic therapies. They are not only promising targets for therapeutic agents but can also potentially serve as prognostic markers in many malignancies.

The authors declare no conflict of interest.

\section{References}

1. Folkman J. Tumour angiogenesis: therapeutic implications. N Engl J Med 1971; 285: 1182-1186. 
2. Wu JB, Tang YL, Liang XH. Targeting VEGF pathway to normalize the vasculature: an emerging insight in cancer therapy. Onco Targets Ther 2018; 11: 6901-6909.

3. Lugano R, Ramachandran M, Dimberg A. Tumour angiogenesis: causes, consequences, challenges and opportunities. Cell Mol Life Sci 2019; 77: 1745-1770.

4. Albo D, Wang TN, Tuszynski GP. Antiangiogenic therapy. Current Pharmaceutical Design 2004; 10: 27-37.

5. Lieu CH, Tran H, Jiang ZQ, et al. The association of alternate VEGF ligands with resistance to anti-VEGF therapy in metastatic colorectal cancer. PLoS One 2013; 8: e77117.

6. Soda Y, Myskiw C, Rommel A, Verma IM. Mechanisms of neovas cularization and resistance to anti-angiogenic therapies in glioblastoma multiforme. J Mol Med (Berl) 2013; 91: 439-448.

7. Pinto MP, Sotomayor P, Carrasco-Avino G, Corvalan AH, Owen GI. Escaping antiangiogenic therapy: strategies employed by cancer cells. Int J Mol Sci 2016; 17: 1489.

8. Yang RY, Rabinovich GA, Liu FT. Galectins: structure, function and therapeutic potential. Expert Rev Mol Med 2008; 10: e17.

9. Cooper DN. Galectinomics: finding themes in complexity. Biochim Biophys Acta 2002; 1572: 209-231.

10. Girotti MR, Salatino M, Dalotto-Moreno T, Rabinovich GA. Sweet ening the hallmarks of cancer: galectins as multifunctional mediators of tumour progression. J Exp Med 2020; 217: e20182041.

11. Dong R, Zhang M, Hu Q, Zheng S, Soh A, Zheng Y, Yuan H. Galec tin-3 as a novel biomarker for disease diagnosis and a target for therapy (review). Int J Mol Med 2018; 41: p. 599-614.

12. Thijssen VL, Postel R, Brandwijk RJMGE. Galectin-1 is essential in tumour angiogenesis and is a target for antiangiogenesis therapy. Proc Natl Acad Sci U S A 2006; 103: 15975-80.

13. Thiemann S, Baum LG. Galectins and immune responses-just how do they do those things they do? Annu Rev Immunol 2016; 34: 243-264.

14. You X, Wang Y, Wu J, Liu Q, Chen D, Tang D, Wang D. Galectin-1 pro motes metastasis in gastric cancer through a sphingosine-1-phos phate receptor 1-dependent mechanism. Cell Physiol Biochem 2018; 51: 11-30

15. Chiyo T, Fujita K, Iwama H, et al. Galectin-9 induces mitochondria-mediated apoptosis of esophageal cancer in vitro and in vivo in a xenograft mouse model. Int J Mol Sci 2019; 20: 2634

16. Griffioen AW, Thijssen VL. Galectins in tumour angiogenesis. Ann Transl Med 2014; 2: 90

17. Croci DO, Cerliani JP, Dalotto-Moreno T, et al. Glycosylation-dependent lectin-receptor interactions preserve angiogenesis in anti VEGF refractory tumours. Cell 2014; 156: 744-758.

18. Van Beijnum JR, Thijssen VL, Läppchen T, et al. A key role for galec tin-1 in sprouting angiogenesis revealed by novel rationally de signed antibodies. Int J Cancer 2016; 139: 824-835.

19. Lotan R, Belloni PN, Tressler RJ, Lotan D, Xu XC, Nicolson GL, et al. Expression of galectins on microvessel endothelial cells and their involvement in tumour cell adhesion. Glycoconj J 1994; 11: 462 468.

20. Clausse N, van den Brûle F, Waltregny D, Garnier F, Castronovo V. Galectin-1 expression in prostate tumour-associated capillary en dothelial cells is increased by prostate carcinoma cells and modu lates heterotypic cell-cell adhesion. Angiogenesis 1999; 3: 317-325.

21. Wei KJ, Pan HY, Yang X, Zhong L, Ye DX, Zhang ZY. [Expression of galectin-1 in carcinogenesis of oral mucosal epithelium]. Zhonghua Kou Qiang Yi Xue Za Zhi 2011; 46: 524-527.

22. Rorive S, Belot N, Decaestecker C, et al. Galectin-1 is highly ex pressed in human gliomas with relevance for modulation of invasion of tumour astrocytes into the brain parenchyma. Glia 2001; 33: 241-255.

23. Aboulhagag NA, El-Deek HEM, Sherif MF. Expression of galectin-1 and galectin-3 in renal cell carcinoma; immunohistochemical study. Ann Diagn Pathol 2018; 36: 31-37.

24. Bacigalupo ML, Carabias P, Troncoso MF. Contribution of galectin-1, a glycan-binding protein, to gastrointestinal tumour progression. World J Gastroenterol 2017; 23: 5266-5281.

25. Yeh CC, Hsu CH, Shao YY, Ho WC, Tsai MH, Feng WC, Chow LP. Integrated stable isotope labeling by amino acids in cell culture (SILAC) and isobaric tags for relative and absolute quantitation
(iTRAO) quantitative proteomic analysis identifies galectin-1 as a potential biomarker for predicting sorafenib resistance in liver cancer. Mol Cell Proteomics 2015; 14: 1527-1545.

26. Tang D, Gao J, Wang S, et al. Cancer-associated fibroblasts promote angiogenesis in gastric cancer through galectin-1 expression. Tumour Biol 2016; 37: 1889-1899.

27. Storti P, Marchica V, Airoldi I, et al. Galectin-1 suppression delineates a new strategy to inhibit myeloma-induced angiogenesis and tumoural growth in vivo. Leukemia 2016; 30: 2351-2363.

28. Pranjol MZI, Zinovkin ZA, Maskell ART, et al. Cathepsin L-induced galectin-1 may act as a proangiogenic factor in the metastasis of high-grade serous carcinoma. J Transl Med 2019; 17: 216.

29. Orozco CA, Martinez-Bosch N, Guerrero PE, et al. Targeting galectin-1 inhibits pancreatic cancer progression by modulating tumour-stroma crosstalk. Proc Natl Acad Sci U S A 2018; 115: E3769-E3778.

30. Wdowiak K, Francuz T, Gallego-Colon E, Ruiz-Agamez N, Kubeczko M, Grochoła I, Wojnar J. Galectin targeted therapy in oncology: current knowledge and perspectives. Int J Mol Sci 2018; 19: 210.

31. Dings RP, Williams BW, Song CW, Griffioen AW, Mayo KH, Griffin RJ. Anginex synergizes with radiation therapy to inhibit tumour growth by radiosensitizing endothelial cells. Int J Cancer 2005; 115: 312-319.

32. Amano M, Suzuki M, Andoh S, et al. Antiangiogenesis therapy using a novel angiogenesis inhibitor, anginex, following radiation causes tumour growth delay. Int J Clin Oncol 2007; 12: 42-47.

33. Dings RP, Yokoyama Y, Ramakrishnan S, Griffioen AW, Mayo KH. The designed angiostatic peptide anginex synergistically improves chemotherapy and antiangiogenesis therapy with angiostatin. Cancer Res 2003; 63: 382-385.

34. Koonce NA, Griffin RJ, Dings RPM. Galectin-1 inhibitor OTX008 induces tumour vessel normalization and tumour growth inhibition in human head and neck squamous cell carcinoma models. Int J Mol Sci 2017; 18: 2671.

35. Kishor C, Ross RL, Blanchard H. Lactulose as a novel template for anticancer drug development targeting galectins. Chem Biol Drug Des 2018; 92: 1801-1808

36. Dumic J, Dabelic S, Flogel M. Galectin-3: an open-ended story. Biochim Biophys Acta 2006; 1760: 616-635.

37. Pricci F, Leto G, Amadio L, et al. Role of galectin-3 as a receptor for advanced glycosylation end products. Kidney Int Suppl 2000; 77: S31-39.

38. Markowska Al, Liu FT, Panjwani N. Galectin-3 is an important mediator of VEGF- and bFGF-mediated angiogenic response. J Exp Med 2010; 207: 1981-1993.

39. Dos Santos SN, Sheldon H, Pereira IX, et al. Galectin-3 acts as an angiogenic switch to induce tumour angiogenesis via Jagged-1/ Notch activation. Oncotarget 2017; 8: 49484-49501.

40. Nabi IR, Shankar J, Dennis JW. The galectin lattice at a glance. J Cell Sci 2015; 128: 2213-2219.

41. Ferreira Cardoso AC, de Sousa Andrade LN, Bustos SO, Chammas R. Galectin-3 determines tumour cell adaptive strategies in stressed tumour microenvironments. Front Oncol 2016; 6: 127.

42. Wang L, Guo XL. Molecular regulation of galectin-3 expression and therapeutic implication in cancer progression. Biomed Pharmacother 2016; 78: 165-171.

43. Cioca A, Muntean D, Bungardean C, Raica M, Cimpean AM. Expression and distribution of galectin-3 in chromophobe and papillary carcinomas. Anticancer Res 2018, 38: 259-263.

44. Wang L, Zhao Y, Wang Y, Wu X. The role of galectins in cervical cancer biology and progression. Biomed Res Int 2018; 2018: 2175927.

45. Duckworth CA, Guimond SE, Sindrewicz P, et al. Chemically modified, non-anticoagulant heparin derivatives are potent galectin-3 binding inhibitors and inhibit circulating galectin-3-promoted metastasis. Oncotarget 2015; 6: 23671-23687.

46. Campo VL, Fiori Marchiori M, Rodrigues LC, Dias-Baruffi M. Synthetic glycoconjugates inhibitors of tumour-related galectin-3: an update. Glycoconj J 2016; 33: 853-876.

47. LaafD,BojarováP,PelantováH,KřenV,EllingL.Tailoredmultivalentneoglycoproteins: synthesis, evaluation, and application of a library of galectin-3-binding glycan ligands. Bioconjug Chem 2017; 28: 2832-2840. 
48. Eliaz I, Raz A. Pleiotropic effects of modified citrus pectin. Nutri ents 2019; 11: 2619.

49. Jayaram S, Kapoor S, Dharmesh SM. Pectic polysaccharide from corn (Zea mays L.) effectively inhibited multi-step mediated cancer cell growth and metastasis. Chem Biol Interact 2015; 235: 63-75.

50. Yao Y, Zhou L, Liao W, et al. HH1-1, a novel Galectin-3 inhibitor, ex erts anti-pancreatic cancer activity by blocking Galectin-3/EGFR/ AKT/FOXO3 signaling pathway. Carbohydr Polym 2019; 204: 111 123.

51. Zhang L, Wang P, Qin Y, et al. RN1, a novel galectin-3 inhibitor, in hibits pancreatic cancer cell growth in vitro and in vivo via blocking galectin-3 associated signaling pathways. Oncogene 2017; 36 1297-1308.

52. Nangia-Makker P, Hogan V, Honjo Y, Baccarini S, Tait L, Bresalier R, Raz A. Inhibition of human cancer cell growth and metastasis in nude mice by oral intake of modified citrus pectin. J Natl Cancer Inst 2002; 94: 1854-1862.

53. Azémar M, Hildenbrand B, Haering B, et al. Clinical benefit in patients with advanced solid tumours treated with modified citrus pectin: a prospective pilot study. Oncology 2007; 1: CMO.S285.

54. Sindrewicz P, Yates EA, Turnbull JE, Lian LY, Yu LG. Interaction with the heparin-derived binding inhibitors destabilizes galectin-3 protein structure. Biochem Biophys Res Commun 2020; 523: 336-341.

55. Wiecikowski A, dos Santos Cabral KM, da Silva Almeida M, Sam paio Carvalho R. Ligand-free method to produce the anti-angiogenic recombinant Galectin-3 carbohydrate recognition domain. Protein Expr Purif 2018; 144: 19-24.

56. Mirandola L, Nguyen DD, Rahman RL, et al. Anti-galectin-3 therapy: a new chance for multiple myeloma and ovarian cancer? Int Rev Immunol 2014; 33: 417-427.

57. Storti P, Marchica V, Giuliani N. Role of galectins in multiple myelo ma. Int J Mol Sci 2017; 18: 2740.

58. Jayakody RS, Wijewardhane P, Herath C, Perera S. Bergenin: a computationally proven promising scaffold for novel galectin-3 inhibi tors. J Mol Model 2018; 24: 302.

59. Troncoso MF, Ferragut F, Bacigalupo ML, et al. Galectin-8: a matricellular lectin with key roles in angiogenesis. Glycobiology 2014; 24: 907-914.

60. Schulz H, Schmoeckel E, Kuhn C, Hofmann S, Mayr D, Mahne $\mathrm{S}$, Jeschke $\mathrm{U}$. Overall survival of ovarian cancer patients is deter mined by expression of galectins-8 and -9 . Int J Mol Sci 2018; 19 : 1230.

61. Gentilini LD, Jaworski FM, Tiraboschi C, et al. Stable and high expression of Galectin- 8 tightly controls metastatic progression of prostate cancer. Oncotarget 2017; 8: 44654-44668.

62. Grosset AA, Labrie M, Vladoiu MC, Yousef EM, Gaboury L, St-Pierre Y. Galectin signatures contribute to the heterogeneity of breast cancer and provide new prognostic information and therapeutic targets. Oncotarget 2016; 7: 18183-18203.

63. Delgado VM, Nugnes LG, Colombo LL, et al. Modulation of endothelial cell migration and angiogenesis: a novel function for the "tandem-repeat" lectin galectin-8. FASEB J 2011; 25: 242-254.

64. Chen C, Duckworth CA, Fu B, Pritchard DM, Rhodes JM, Yu LG. Circulating galectins $-2,-4$ and -8 in cancer patients make important contributions to the increased circulation of several cytokines and chemokines that promote angiogenesis and metastasis. Br J Cancer 2014; 110: 741-752.

65. Oyanadel C, Holmes C, Pardo E, et al. Galectin-8 induces partial epithelial-mesenchymal transition with invasive tumourigenic capabilities involving a FAK/EGFR/proteasome pathway in Madin-Darby canine kidney cells. Mol Biol Cell 2018; 29: 557-574.

66. Zamorano P, Koning T, Oyanadel C, et al. Galectin-8 induces endothelial hyperpermeability through the eNOS pathway involving S-nitrosylation-mediated adherens junction disassembly. Carcinogenesis 2019; 40: 313-323.

67. Heusschen R, Schulkens IA, van Beijnum J, Griffioen AW, Thijssen VL Endothelial LGALS9 splice variant expression in endothelial cell biol ogy and angiogenesis. Biochim Biophys Acta 2014; 1842: 284-292.

68. Thijssen VL, Griffioen AW. Galectin-1 and -9 in angiogenesis: a sweet couple. Glycobiology 2014; 24: 915-920.

69. Aanhane E, Schulkens IA, Heusschen R, Castricum K, Leffler H, Griffioen AW, Thijssen VL. Different angioregulatory activity of monovalent galectin-9 isoforms. Angiogenesis 2018; 21: 545-555.
70. Enninga EAL, Chatzopoulos K, Butterfield JT, et al. CD206-positive myeloid cells bind galectin- 9 and promote a tumour-supportive microenvironment. J Pathol 2018; 245: 468-477.

71. Goodman AR, Cardozo T, Abagyan R, Altmeyer A, Wisniewski HG, Vilcek J. Long pentraxins: an emerging group of proteins with diverse functions. Cytokine Growth Factor Rev 1996; 7: 191-202.

72. Garlanda C, Bottazzi B, Salvatori G, et al. Pentraxins in innate im munity and inflammation. Novartis Found Symp 2006; 279: 80-86, discussion 86-91, 216-219.

73. Ma YJ, Garred P. Pentraxins in complement activation and regulation. Front Immunol 2018; 9: 3046.

74. Mantovani A, Garlanda C, Doni A, Bottazzi B. Pentraxins in innate immunity: from C-reactive protein to the long pentraxin PTX3. J Clin Immunol 2008; 28: 1-13.

75. Giacomini A, Ghedini GC, Presta M, Ronca R. Long pentraxin 3: A novel multifaceted player in cancer. Biochim Biophys Acta Rev Cancer 2018; 1869: 53-63.

76. Camozzi M, Rusnati M, Bugatti A, et al. Identification of an antiangiogenic FGF2-binding site in the $\mathrm{N}$ terminus of the soluble pattern recognition receptor PTX3. J Biol Chem 2006; 281: 22605-22613.

77. Rusnati M, Camozzi M, Moroni E, et al. Selective recognition of fibroblast growth factor-2 by the long pentraxin PTX3 inhibits angiogenesis. Blood 2004; 104: 92-99.

78. Ronca R, Alessi P, Coltrini D, et al. Long pentraxin-3 as an epithelial-stromal fibroblast growth factor-targeting inhibitor in prostate cancer. J Pathol 2013; 230: 228-238.

79. Rodrigues PF, Matarazzo S, Maccarinelli F, et al. Long pentraxin 3-mediated fibroblast growth factor trapping impairs fibrosarcoma growth. Front Oncol 2018; 8: 472.

80. Annese T, Ronca R, Tamma R, et al. PTX3 modulates neovascularization and immune inflammatory infiltrate in a murine model of fibrosarcoma. Int J Mol Sci 2019; 20: 4599.

81. Ronca R, Giacomini A, di Salle E, et al. Long-pentraxin 3 derivative as a small-molecule fgf trap for cancer therapy. Cancer Cell 2015; 28: 225-239.

82. Ronca R, Tamma R, Coltrini D, Ruggieri S, Presta M, Ribatti D. Fibroblast growth factor modulates mast cell recruitment in a murine model of prostate cancer. Oncotarget 2017; 8: 82583-82592.

83. Castelli R, Giacomini A, Anselmi M, et al. Synthesis, structural elucidation, and biological evaluation of NSC12, an orally available fibroblast growth factor (FGF) ligand trap for the treatment of FGF-dependent lung tumours. J Med Chem 2016; 59: 4651-4663.

84. Rezzola S, Ronca R, Loda A, et al. The autocrine FGF/FGFR system in both skin and uveal melanoma: FGF trapping as a possible therapeutic approach. Cancers (Basel) 2019; 11: 1305.

85. Leali D, Alessi P, Coltrini D, et al. Long pentraxin-3 inhibits fgf8b-dependent angiogenesis and growth of steroid hormone-regulated tumours. Mol Cancer Ther 2011; 10: 1600-1610.

86. Hida K, Maishi N, Kawamoto T, et al. Tumour endothelial cells express high pentraxin 3 levels. Pathol Int 2016; 66: 687-694.

87. Kondo S, Ueno H, Hosoi H, et al. Clinical impact of pentraxin family expression on prognosis of pancreatic carcinoma. Br J Cancer 2013; 109: 739-746

88. Ying $\mathrm{TH}$, Lee $\mathrm{CH}$, Chiou HL, et al. Knockdown of Pentraxin 3 suppresses tumourigenicity and metastasis of human cervical cancer cells. Sci Rep 2016; 6: 29385.

89. Locatelli M, Ferrero S, Boneschi FM, et al. The long pentraxin PTX3 as a correlate of cancer-related inflammation and prognosis of malignancy in gliomas. J Neuroimmunol 2013; 260: 99-106.

90. Tung JN, Ko CP, Yang SF, et al. Inhibition of pentraxin 3 in glioma cells impairs proliferation and invasion in vitro and in vivo. J Neurooncol 2016; 129: 201-209.

91. Stallone G, Cormio L, Netti GS, et al. Pentraxin 3: a novel biomarker for predicting progression from prostatic inflammation to prostate cancer. Cancer Res 2014; 74: 4230-4238.

92. Infante M, Allavena P, Garlanda C, et al. Prognostic and diagnostic potential of local and circulating levels of pentraxin 3 in lung cancer patients. Int J Cancer 2016; 138: 983-991.

93. Willeke F, Assad A, Findeisen P, et al. Overexpression of a member of the pentraxin family (PTX3) in human soft tissue liposarcoma. Eur J Cancer 2006; 42: 2639-2646.

94. Chang WC, Wu SL, Huang WC, et al. PTX3 gene activation in EGF-induced head and neck cancer cell metastasis. Oncotarget 2015; 6 : $7741-7757$. 
95. Choi B, Lee EJ, Shin MK, et al. Upregulation of brain-derived neurotrophic factor in advanced gastric cancer contributes to bone metastatic osteolysis by inducing long pentraxin 3. Oncotarget 2016; 7: 55506-55517.

96. Choi B, Lee EJ, Song DH, et al. Elevated Pentraxin 3 in bone metastatic breast cancer is correlated with osteolytic function. Oncotarget 2014; 5: 481-492.

97. Billhaq DH, Lee S. A potential function of RLIP76 in the ovarian corpus luteum. J Ovarian Res 2019; 12: 34.

98. Lee S, Wurtzel JGT, Singhal SS, Awasthi S, Goldfinger LE. RALBP1/ RLIP76 depletion in mice suppresses tumour growth by inhibiting tumour neovascularization. Cancer Res 2012; 72: 5165-5173.

99. Lee S, Goldfinger LE. RLIP76 regulates HIF-1 activity, VEGF expression and secretion in tumour cells, and secretome transactivation of endothelial cells. FASEB J 2014; 28: 4158-4168.

100.Wang W, Liu J, Qi J, et al. RLIP76 increases apoptosis through Akt/ mTOR signaling pathway in gastric cancer. Oncol Rep 2016; 36: 2216-2224.

101. Mott HR, Owen D. Structure and function of RLIP76 (RalBP1): an intersection point between Ras and Rho signalling. Biochem Soc Trans 2014; 42: 52-58.

102. Singhal J, Nagaprashantha L, Chikara S, et al. 2'-Hydroxyflavanone: a novel strategy for targeting breast cancer. Oncotarget 2017; 8: 75025-75037.

103. Fan SY, Jiang JD, Qian J, et al. Overexpression of RLIP76 required for proliferation in meningioma is associated with recurrence. PLoS One 2015; 10: e0125661.

104. Yan J, Liu Q, Dou Y, et al. Activating glucocorticoid receptor-ERK signaling pathway contributes to ginsenoside Rg1 protection against beta-amyloid peptide-induced human endothelial cells apoptosis. J Ethnopharmacol 2013; 147: 456-466.

105. Wurtzel JG, Lee S, Singhal SS, Awasthi S, Ginsberg MH, Goldfinger LE. RLIP76 regulates Arf6-dependent cell spreading and migration by linking ARNO with activated R-Ras at recycling endosomes. Biochem Biophys Res Commun 2015; 467: 785-791.

106. Lee S, Wurtzel JG, Goldfinger LE. The RLIP76 N-terminus binds ARNO to regulate PI 3-kinase, Arf6 and Rac signaling, cell spreading and migration. Biochem Biophys Res Commun 2014; 454: 560-565.

107. Wang CZ, Yuan P, Xu B, Yuan L, Yang HZ, Liu X, et al. RLIP76 expression as a prognostic marker of breast cancer. Eur Rev Med Pharmacol Sci 2015; 19: 2105-2111.

108. Awasthi S, Singhal SS, Singhal J, et al. Anticancer activity of 2'-hydroxyflavanone towards lung cancer. Oncotarget 2018; 9: 36202 36219.

109. Singhal J, Chikara S, Horne D, Salgia R, Awasthi S, Singhal SS. 2'-Hydroxyflavanone inhibits in vitro and in vivo growth of breast cancer cells by targeting RLIP76. Mol Carcinog 2018; 57: 1751-1762.

110. Nagaprashantha LD, Singhal J, Li H, et al. 2'-Hydroxyflavanone effectively targets RLIP76-mediated drug transport and regulates critical signaling networks in breast cancer. Oncotarget 2018; 9: 18053-18068.

111. Yang J, Song Q, Cai Y, Wang P, Wang M, Zhang D. RLIP76-dependent suppression of $\mathrm{PI} 3 \mathrm{~K} / \mathrm{AKT} / \mathrm{BCl}-2$ pathway by miR-101 induces apoptosis in prostate cancer. Biochem Biophys Res Commun 2015; 463: 900-906.

112. Kumar MM, Goyal R. LncRNA as a therapeutic target for angiogenesis. Curr Top Med Chem 2017; 17: 1750-1757.

113. George J, Patel T. Noncoding RNA as therapeutic targets for hepatocellular carcinoma. Semin Liver Dis 2015; 35: 63-74.

114. Qin WW, Qin W, Xin ZL, Wang Hq, Wang KP, Li XY, Wang X. Inhibiting IncRNA ROR suppresses growth, migration and angiogenesis in microvascular endothelial cells by up-regulating miR-26. Eur Rev Med Pharmacol Sci 2018; 22: 7985-7993.

115. Rinn JL, Chang HY. Genome regulation by long noncoding RNAs. Annu Rev Biochem 2012; 81: 145-166.

116. Wang KC, Chang HY. Molecular mechanisms of long noncoding RNAs. Mol Cell 2011; 43: 904-914.

117. Qin L, Zhong M, Adah D, et al. A novel tumour suppressor IncRNA F630028010Rik inhibits lung cancer angiogenesis by regulating miR-223-3p. J Cell Mol Med 2020; 24: 3549-3559.
118. De Los Santos MC, Dragomir MP, Calin GA, The role of exosomal long non-coding RNAs in cancer drug resistance. Cancer Drug Resist 2019; 2: 1178-1192.

119. Zhu CY, Fan CR, Zhang YL, et al. LncRNA DANCR affected cell growth, EMT and angiogenesis by sponging miR-345-5p through modulating Twist1 in cholangiocarcinoma. Eur Rev Med Pharmacol Sci 2020; 24: 2321-2334.

120. Zhao J, Du P, Cui P, et al. LncRNA PVT1 promotes angiogenesis via activating the STAT3/VEGFA axis in gastric cancer. Oncogene 2018; 37: 4094-4109.

121. Fu WM, Lu JF, Hu BG, et al. Long noncoding RNA Hotair mediated angiogenesis in nasopharyngeal carcinoma by direct and indirect signaling pathways. Oncotarget 2016; 7: 4712-4723.

122. Michalik KM, You X, Manavski Y, et al. Long noncoding RNA MALAT1 regulates endothelial cell function and vessel growth. Circ Res 2014; 114: 1389-1397.

123. Puthanveetil P, Chen S, Feng B, Gautam A, Chakrabarti S. Long non-coding RNA MALAT1 regulates hyperglycaemia induced inflammatory process in the endothelial cells. J Cell Mol Med 2015; 19): 1418-1425.

124. Zhang X, Zhang X, Tang X, Hamblin MH, Yin KJ. long non-coding RNA malat1 regulates angiogenesis in hindlimb ischemia. Int J Mol Sci 2018; 19: 1723.

125. Li K, Blum Y, Verma A, et al. A noncoding antisense RNA in tie-1 locus regulates tie-1 function in vivo. Blood 2010; 115: 133-139.

126. Yuan SX, Yang F, Yang Y, et al. Long noncoding RNA associated with microvascular invasion in hepatocellular carcinoma promotes angiogenesis and serves as a predictor for hepatocellular carcinoma patients' poor recurrence-free survival after hepatectomy. Hepatology 2012; 56: 2231-2241.

127. Zhu Y, Zhang X, Qi L, Cai Y, Yang P, Xuan G, Jiang Y. HULC long noncoding RNA silencing suppresses angiogenesis by regulating ESM1 via the PI3K/Akt/mTOR signaling pathway in human gliomas. Oncotarget 2016; 7: 14429-14440.

128. Jin SJ, Jin MZ, Xia BR, Jin WL. Long non-coding RNA DANCR as an emerging therapeutic target in human cancers. Front Oncol 2019; 9: 1225.

129. Shen X, Bai Y, Luo B, Zhou X. Upregulation of IncRNA BANCR associated with the lymph node metastasis and poor prognosis in colorectal cancer. Biol Res 2017; 50: 32.

130. Lin X, Yang F, Qi X, et al. LncRNA DANCR promotes tumour growth and angiogenesis in ovarian cancer through direct targeting of miR-145. Mol Carcinog 2019; 58: 2286-2296.

131. Onagoruwa OT, Pal G, Ochu C, Ogunwobi OO. Oncogenic role of PVT1 and therapeutic implications. Front Oncol 2020; 10: 17.

132. Xu MD, Wang Y, Weng W, et al. A positive feedback loop of InCRNA-PVT1 and FOXM1 facilitates gastric cancer growth and invasion. Clin Cancer Res 2017; 23: 2071-2080.

133. Kurian L, Aguirre A, Sancho-Martinez I, et al. Identification of novel long noncoding RNAs underlying vertebrate cardiovascular development. Circulation 2015; 131: 1278-1290.

134. Klattenhoff CA, Scheuermann JC, Surface LE, et al. Braveheart, a long noncoding RNA required for cardiovascular lineage commitment. Cell 2013; 152: 570-583.

135. Grote P, Wittler L, Hendrix D, et al. The tissue-specific IncRNA Fendrr is an essential regulator of heart and body wall development in the mouse. Dev Cell 2013; 24: 206-214.

136. Zhao Z, Sun W, Guo Z, Zhang J, Yu H, Liu B. Mechanisms of IncRNA/ microRNA interactions in angiogenesis. Life Sci 2020; 254: 116900.

137. Ni L, Dong C. New B7 family checkpoints in human cancers. Mol Cancer Ther 2017; 16: 1203-1211.

138. Chapoval Al, Ni J, Lau JS, et al. B7-H3: a costimulatory molecule for $T$ cell activation and IFN-gamma production. Nat Immunol 2001; 2 : 269-274.

139. Zhou YH, Chen YJ, Ma ZY, et al. 4lgB7-H3 is the major isoform expressed on immunocytes as well as malignant cells. Tissue Antigens 2007; 70: 96-104.

140. Ling V, Wu PW, Spaulding V, Kieleczawa J, Luxenberg D, Carreno BM, Collins M. Duplication of primate and rodent B7-H3 immunoglobulin $\mathrm{V}$ - and C-like domains: divergent history of functional redundancy and exon loss. Genomics 2003; 82: 365-377. 
141. Picarda E, Ohaegbulam KC, Zang X, Molecular pathways: targeting B7-H3 (CD276) for human cancer immunotherapy. Clin Cancer Res 2016; 22: 3425-3431.

142. Wang Z, Wang Z, Zhang C, et al. Genetic and clinical characterization of B7-H3 (CD276) expression and epigenetic regulation in diffuse brain glioma. Cancer Sci 2018; 109: 2697-2705.

143. Son Y, Kwon SM, Cho JY. CD276 (B7-H3) maintains proliferation and regulates differentiation in angiogenic function in late endothelial progenitor cells. Stem Cells 2019; 37: 382-394.

144. Wang R, Ma Y, Zhan S, et al. B7-H3 promotes colorectal cancer angiogenesis through activating the NF-kappaB pathway to induce VEGFA expression. Cell Death Dis 2020; 11: 55.

145. Oeckinghaus A, Ghosh S. The NF-kappaB family of transcription factors and its regulation. Cold Spring Harb Perspect Biol 2009; 1: a000034.

146. Zeligs KP, Neuman MK, Annunziata CM. Molecular pathways: the balance between cancer and the immune system challenges the therapeutic specificity of targeting nuclear factor-kappab signaling for cancer treatment. Clin Cancer Res 2016; 22: 4302-4308.

147. Han S, Wang Y, Shi X, et al. Negative roles of B7-H3 and B7-H4 in the microenvironment of cervical cancer. Exp Cell Res 2018; 371: 222-230.

148. Freise N, Burghard A, Ortkras T, et al. Signaling mechanisms inducing hyporesponsiveness of phagocytes during systemic inflammation. Blood 2019; 134: 134-146.

149. Chen YW, Tekle C, Fodstad O. The immunoregulatory protein human $\mathrm{B} 7 \mathrm{H} 3$ is a tumour-associated antigen that regulates tumour cell migration and invasion. Curr Cancer Drug Targets 2008; 8: 404-413.

150. Liu F, Zhang T, Zou S, Jiang B, Hua D. B7H3 promotes cell migration and invasion through the Jak2/Stat3/MMP9 signaling pathway in colorectal cancer. Mol Med Rep 2015; 12: 5455-5460.

151. Tekle C, Nygren MK, Chen YW, et al. B7-H3 contributes to the metastatic capacity of melanoma cells by modulation of known metastasis-associated genes. Int J Cancer 2012; 130: 2282-2290.

152. Lim S, LiuH, Madeira da Silva L, et al. Immunoregulatory Protein B7H3 Reprograms Glucose Metabolism in Cancer Cells by ROS-Mediated Stabilization of HIF1alpha. Cancer Res 2016; 76: 2231-2242.

153. Itoh K, Chiba T, Takahashi S, et al. An Nrf2/small Maf heterodimer mediates the induction of phase II detoxifying enzyme genes through antioxidant response elements. Biochem Biophys Res Commun 1997; 236: 313-322.

154. Inamura K, Amori G, Yuasa T, Yamamoto S, Yonese J, Ishikawa Y Relationship of B7-H3 expression in tumour cells and tumour vasculature with FOXP3+ regulatory $T$ cells in renal cell carcinoma. Cancer Manag Res 2019; 11: 7021-7030.

155. Xu ZL, Zhang Y, Wang L, Li F, Man HW, Li PF, Shan BE. B7H3 promotes malignant progression of muscleinvasive bladder cancer. Oncol Rep 2018; 40: 2722-2733.

156. Inamura K, Takazawa Y, Inoue Y. Tumour B7-H3 (CD276) expression and survival in pancreatic cancer. J Clin Med 2018; 7: 172

157. Pizon M, Schott DS, Pachmann U, Pachmann K. B7-H3 on circulating epithelial tumour cells correlates with the proliferation marker, Ki-67, and may be associated with the aggressiveness of tumours in breast cancer patients. Int J Oncol 2018; 53: 2289-2299.

158. He L, Li Z. B7-H3 and its role in bone cancers. Pathol Res Pract 2019; 215: 152420.

159. Bao R, Wang Y, Lai J, et al. Enhancing anti-PD-1/PD-L1 immune checkpoint inhibitory cancer therapy by CD276-targeted photodynamic ablation of tumour cells and tumour vasculature. Mol Pharm 2019; 16: 339-348.

160. Yamamoto S, Schulze KL, Bellen HJ. Introduction to Notch signaling. Methods Mol Biol 2014; 1187: 1-14.

161. Fleming RJ. Structural conservation of Notch receptors and ligands. Semin Cell Dev Biol 1998; 9: 599-607.

162. Benedito R, Duarte A. Expression of Dll4 during mouse embryogenesis suggests multiple developmental roles. Gene Expr Patterns 2005; 5: 750-755.

163. Noguera-Troise I, Daly C, Papadopoulos NJ, et al. Blockade of Dll4 inhibits tumour growth by promoting non-productive angiogenesis. Nature 2006; 444: 1032-1037.

164. Duarte A, Hirashima M, Benedito R, et al. Dosage-sensitive requirement for mouse Dll4 in artery development. Genes Dev 2004; 18 : 2474-2478.
165. Lobov IB, Renard RA, Papadopoulos N, Gale NW, Thurston G, Yancopoulos GD, Wiegand SJ. Delta-like ligand 4 (DIl4) is induced by VEGF as a negative regulator of angiogenic sprouting. Proc Natl Acad Sci U S A 2007; 104: 3219-3224.

166. Patel NS, Li J, Generali D, Poulsom R, Cranston DW, Harris AL. Up-regulation of delta-like 4 ligand in human tumour vasculature and the role of basal expression in endothelial cell function. Cancer Res 2005; 65: 8690-8697.

167. Sacilotto N, Monteiro R, Fritzsche M, et al. Analysis of Dll4 regulation reveals a combinatorial role for Sox and Notch in arterial development. Proc Natl Acad Sci U S A 2013; 110: 11893-11898.

168. Muller H, Hu J, Popp R, et al. Deleted in malignant brain tumours 1 is present in the vascular extracellular matrix and promotes angiogenesis. Arterioscler Thromb Vasc Biol 2012; 32: 442-448.

169. Ridgway J, Zhang G, Wu Y, et al. Inhibition of DIl4 signalling inhibits tumour growth by deregulating angiogenesis. Nature 2006; 444 1083-1087.

170. Scehnet JS , Jiang W, Kumar SR, et al. Inhibition of Dll4-mediated signaling induces proliferation of immature vessels and results in poor tissue perfusion. Blood 2007; 109: 4753-4760.

171. Yamanda S, Ebihara S, Asada M, et al. Role of ephrinB2 in nonproductive angiogenesis induced by Delta-like 4 blockade. Blood 2009; 113: 3631-369.

172. Shah AV, Birdsey GM, Peghaire C, et al. The endothelial transcription factor ERG mediates Angiopoietin-1-dependent control of Notch signalling and vascular stability. Nat Commun 2017; 8: 16002

173. Skuli N, Liu L, Runge A, et al. Endothelial deletion of hypoxia-inducible factor-2alpha (HIF-2alpha) alters vascular function and tumour angiogenesis. Blood 2009; 114: 469-477.

174. Corada M, Nyqvist D, Orsenigo F, et al. The Wnt/beta-catenin pathway modulates vascular remodeling and specification by upregulating DIl4/Notch signaling. Dev Cell 2010; 18: 938-949.

175. Eilken HM, Adams RH. Dynamics of endothelial cell behavior in sprouting angiogenesis. Curr Opin Cell Biol 2010; 22: 617-625.

176. Mendonça L, Trindade A, Carvalho C, Correia J, Badenes M, Gigate J, Duarte A. Metastasis is impaired by endothelial-specific DII4 loss-of-function through inhibition of epithelial-to-mesenchymal transition and reduction of cancer stem cells and circulating tumour cells. Clin Exp Metastasis 2019; 36: 365-380.

177. Wang Y, Trindade A, Carvalho C, et al. Evaluation of the correlation of vasculogenic mimicry, Notch4, DLL4, and KAI1/CD82 in the prediction of metastasis and prognosis in non-small cell lung cancer. Medicine (Baltimore) 2018; 97: e13817.

178. Iwamoto H, Zhang Y, Seki T, et al. PIGF-induced VEGFR1-dependent vascular remodeling determines opposing antitumour effects and drug resistance to Dll4-Notch inhibitors. Sci Adv 2015; 1: e1400244.

179. Zhou R, Wang S, Wen H, Wang M, Wu M. The bispecific antibody HB-32, blockade of both VEGF and DLL4 shows potent anti-angiogenic activity in vitro and anti-tumour activity in breast cancer xenograft models. Exp Cell Res 2019; 380: 141-148

180. Xu Z, Wang Z, Jia X, et al. MMGZO1, an anti-DLL4 monoclonal antibody, promotes nonfunctional vessels and inhibits breast tumour growth. Cancer Lett 2016; 372: 118-127.

181. Jia X, Wang W, Zhuobin Xu, et al. A humanized anti-DLL4 antibody promotes dysfunctional angiogenesis and inhibits breast tumour growth. Sci Rep 2016; 6: 27985.

182. Chiorean EG, LoRusso P, Strother RM, et al. A phase i first-in-human study of enoticumab (REGN421), a fully human delta-like ligand 4 (DII4) monoclonal antibody in patients with advanced solid tumours. Clin Cancer Res 2015; 21: 2695-2703.

\section{Address for correspondence}

\section{Marta Magdalena Fudalej}

Department of Cancer Prevention

Medical University of Warsaw

81 Żwirki i Wigury St.

02-091 Warsaw, Poland

e-mail: marta.fudalej@wum.edu.pl

Submitted: 14.10 .2020

Accepted: 23.11.2020 